\title{
CÁNTICO DE LAS SIETE ESTRELLAS, DE ANTÓN GARCÍA ABRIL: HACIA UNA CONSTRUCCIÓN COLECTIVA DEL SIGNIFICADO
}

\author{
ANTÓN GARCIA ABRIL'S CÁNTICO DE LAS SIETE ESTRELLAS: TOWARDS A \\ COLLECTIVE CONSTRUCTION OF MEANING
}

\author{
Juan José Pastor Comín \\ Centro de Investigación y Documentación Musical (Unidad Asociada al CSIC) \\ Universidad de Castilla-La Mancha \\ juanjose.pastor@uclm.es \\ ORCID iD: http://orcid.org/0000-0001-8165-1232
}

\begin{abstract}
Resumen
La cantata para coro y orquesta Cántico de las siete estrellas, de Antón García Abril, surge como una obra comisionada por la Comunidad de Madrid en el año 2004. Inspirado por la constelación de estrellas que circunda el escudo de la Villa, por primera vez en toda su producción vocal el compositor decide escribir él mismo un texto que se apoya en la tradición literaria humanística del XVI, dentro del marco paradigmático del hombre como un pequeño mundo o microcosmos cuya observación del universo es regida por los principios astronómicos y musicales del macrocosmos, tal y como se explicaba en el Quadrivium del medioevo. El atentado terrorista del 11.03.2004, meses antes de su estreno, no solo motivó la dedicatoria de esta obra a sus víctimas, sino que transformó la construcción de un sentido personal y privado en un nuevo signifi cado social y colectivo. Este trabajo propone un examen detallado del contexto de su creación y vida performativa, fi liación literaria, vinculación con la expresión del dolor ante la barbarie terrorista y un análisis musical que revele los instrumentos compositivos puestos al servicio de la palabra transformada por la realidad.
\end{abstract}

\section{Palabras clave}

Antón García Abril; Análisis musical; Humanismo; Terrorismo; Construcción social del significado; Cantata; Madrid.

\section{INTRODUCCIÓN}

El 27.04.2004, la Orquesta y Coro de la Comunidad de Madrid, bajo la dirección de José Ramón Encinar, estrenaba en el Auditorio Nacional Cántico de las siete estrellas de Antón García Abril sobre un texto propio, cantata escrita para coro

(C) 2018 CSIC. Este es un artículo de acceso abierto distribuido bajo los términos de una licencia de uso y distribución Creative Commons Attribution 4.0 International (CC BY 4.0)

Cómo citar este artículo/Citation: Pastor Comín, J. J. (2018). Cántico de las siete estrellas, de Antón García Abril: hacia una construcción colectiva del significado. Anuario Musical, 73: 297-310. doi: http://dx.doi.org/10.3989/redc.2018.73.21

\begin{abstract}
The cantata for choir and orchestra Cántico de las siete estrellas, by Antón García Abril, was commissioned by the Community of Madrid in 2004. Inspired by the constellation of stars that surrounds the coat of arms of the Town, for the first time in all his vocal production the composer decides to write himself a text that is based on the humanistic literary tradition of the 16th century, within the paradigmatic framework of man as a small world or microcosm whose observation of the universe is governed by the astronomical and musical principles of the macrocosm, as it was explained in the Quadrivium of the Middle Ages. The terrorist attack of March 11, 2004 , months before its premiere, not only motivated the dedication of this work to the victims, but also transformed the construction of a personal and private sense into a new social and collective meaning. This work proposes a detailed examination of the context of his creation and performative life, literary filiation, the expression of pain in the face of terrorist barbarism, and a musical analysis that reveals the compositional instruments placed at the service of the word transformed by reality.
\end{abstract}

\section{Key words \\ Musical analysis; Humanism; Terrorism; Social construction of meaning; Cantata; Madrid. \\ y orquesta por encargo de la propia Comunidad de Madrid ${ }^{1}$. Unos días más tarde, Antonio Iglesias dejaba constancia de su}

1 Antón García Abril (1933) no requiere glosa alguna por ser una de las figuras capitales en el ámbito de la composición española contemporánea. Entre sus muchos reconocimientos está el de ser miem- 
impresión -“Cántico a la paz y a los pueblos"-, en el diario ABC:

Programa muy interesante, yendo de la presentación de un joven solista, el recuerdo a un afamado italiano en el mes anterior al del primer aniversario de su muerte, y nuevo estreno de Antón García Abril: su «Cántico de las siete estrellas», obra-encargo de la Consejería de Cultura y Deportes de la Comunidad de Madrid, «sobre el símbolo de las siete estrellas, tan antiguo», como desconocido, añado por mi parte. Para ello, el propio músico turolense redactó un poema precioso, con palabras que aluden al hombre y los cielos, la paz y los pueblos, etc., etc. Su música, la cual siempre canta, la que da razón al dicho de Schoenberg: «Todavía pueden decirse cosas en Do mayor», o algo así, se plantea desde una plantilla que reduce la cuerda y las trompas e incluye tres percusionistas, arpa, celesta y piano, además de un coro que dice el texto con esencial protagonismo, delicadamente o llegando a la exclamación; es obra de maestro, desde su emotiva iniciación hasta el musitando final, pasando por sutiles delicadezas suscritas de sencilla manera. Su cuidado trazo sinfónico-coral vuelve a denotarse como personal y, rozando los 20 minutos de duración, suma enteros firmes en el catálogo de García Abril. Lo hizo muy bien, con claridad y alma, José Ramón Encinar. Con respuesta convincente de la Orquesta y Coro de la Comunidad de Madrid, tras una esplendorosa traducción de «La Ritirata Notturna di Madrid», de Luigi Boccherini-Luciano Berio, artífices valiosos de una colaboración esforzada en el «Tercer Concerto», de Sergei Rachmaninov, en el que lució su categoría de pianista excepcional el ruso de veinte años Boris Giltbur $[\ldots]^{2}$.

Sorprende desde un primer momento la extrañeza del crítico ante el tema central de una obra que, por las circunstancias previas a su estreno, el propio compositor dedicó "a las víctimas del 11-M"3. La génesis de la misma, no obstante, procede del encargo que le había trasladado la Comunidad de Madrid

bro de la Real Academia de Bellas Artes de San Fernando de Madrid desde 1988; correspondiente de la Academia de Nobles y Bellas Artes de San Luis de Zaragoza en 1995 y Académico de Honor de dicha Academia en el 2003; correspondiente de la Academia de Bellas Artes Nuestra Señora de las Angustias de Granada en 1997; de la Academia Nacional de las Bellas Artes de la República Argentina en el 2000; y, en 2001, correspondiente de la Real Academia de Bellas Artes de Santa Isabel de Hungría de Sevilla. A estos reconocimientos hay que añadir el Premio Nacional de Música (1993), la Medalla de Oro al Mérito de las Bellas Artes (1998) el Premio Iberoamericano de la Música Tomás Luis de Vitoria (2006), el Premio de Cultura de la Comunidad de Madrid (2006), el Premio Nacional del Teatro (1971), Premio Fundación Guerrero (1993), o la Medalla de Oro de la Academia Española de Cine (2014). Remitimos aquí a los mejores estudios de conjunto sobre su figura: CARBÓ (2016), CABAÑAS (1993), RUIZ TARAZONA (2005), SESTELO (2006) y ZALDÍVAR (2003): 7-85.

2 IGLESIAS (2004): 60.

3 GARCÍA ABRIL (2006): I. años antes y para el cual anduvo documentándose durante largo tiempo con el fin de alcanzar un texto que vertebrara adecuadamente su proyecto compositivo ${ }^{4}$. Tras desestimar varias posibles fuentes, entre ellas las del folklore propiciado por Manuel García Matos, Antón García Abril refiere su decisión final sobre la armazón textual de esta obra:

después de un tiempo dedicado a la lectura de poemas en los que las estrellas fuesen elementos de inspiración poética, no llegué a identificarme con ellos [...] Teniendo una idea muy concreta de la obra que quería realizar, me introduje en un camino de intuiciones líricas en torno a la constelación de la Osa Mayor y, tal vez, lleno de osadía escribí mi propio texto, el texto que, como compositor, necesitaba para dar forma a mi idea compositiva aunando el contenido poético -el primer pulso compositivo de una cantata necesariamente nace de la palabra- con sus propias posibilidades de desarrollo musical ${ }^{5}$.

Nace así el texto "Cántico de las siete estrellas" -cuyo análisis realizaremos más adelante con detalle- como una excepción de adscripción autorial singular dentro del conjunto de su obra no escénica destinada a la voz solista o coro y orquesta, y para la que hasta entonces el compositor siempre había trabajado sobre textos prestados. Sucede así con Tres canciones españolas (1962) sobre tres poemas de Federico García Lorca ${ }^{6}$; Cantico delle creature (1964), sobre textos de San Francisco de Asís 7 ;

4 "Desde que se me propone escribir la obra encargo de la Orquesta y Coro de la Comunidad de Madrid han transcurrido ya varios años, pero no han sido baldíos para mí, porque, desde aquel momento hasta el año 2003, que inicio la realización de la partitura, ha ido gestándose y tomando forma lo que en principio era solamente un proyecto, una intuición y un deseo. En el primer período me basé en la posibilidad de escribir la cantata solicitando algún texto escrito ex profeso por alguno de nuestros poetas. [...] Desechando esta idea, y siguiendo los caminos de búsqueda, me acerqué a la música popular de Madrid [...] Después de algún tiempo trabajando en esta dirección, acopiando y seleccionando documentos musicales y estudiando sus posibilidades de desarrollo sinfónico-coral, lo abandoné al no satisfacer plenamente mis necesidades para estructurar una obra de caracteres plenamente identificados con una obra sinfónico-coral. En este nuevo camino que inicio, dando un viraje muy marcada a los anteriores bocetos, me acerco a un espacio poético por los impulsos que me sugiere el símbolo de nuestra Comunidad, entendido desde una visión íntima y lírica. Así nace, definitivamente, este Cántico de las siete estrellas", GARCIA ABRIL (2004): 3 .

5 Ibidem. Vid. también el trabajo de CORONAS (2008): 173-174 y CORONAS (2010).

6 Compuestas sobre los poemas "Zorongo", "Nana, niño, nana", de Bodas de Sangre y la "Baladilla de los tres ríos", fue cantada por Inés Rivadeneira bajo la dirección de Louis de Froment en Luxemburgo, por la Orquesta Sinfónica de la Radiotelevisión de Luxemburgo.

7 Concebida para el décimo aniversario de la muerte de Ataúlfo Argenta, esta obra fue estrenada el 20 de enero de 1968 en el Auditorio del Ministerio de Información y Turismo bajo la dirección de Alberto Blancafort al frente del Coro de Radiotelevisión Española y de Enrique García Asensio en la Orquesta Sinfónica de Radiotelevisión Española. 
Homenaje a Miguel Hernández (1965) textos de Rafael Alberti (1969)"; Cántico de "La Pietà" (1977), con textos de Antonio Gala ${ }^{10}$; Alegrías (1979), con poemas de Marina Romero ${ }^{11}$; sus Canciones asturianas (1984), sobre composiciones líricas de José León Delestal ${ }^{12}$; el Salmo de Alegría para el Siglo XXI (1988), con letra de Rafael Alberti ${ }^{13}$; el Himno de Aragón (1988) ${ }^{14}$; las Cancions Xacobeas (1993), de distintos poetas gallegos ${ }^{15}$; la cantata Lur Kantak (1997), sobre canciones vascas ${ }^{16}$; el Himno de la Universidad Carlos III (1999), con letra de Jorge Urrutia ${ }^{17}$; los Dos Villancicos para el nuevo milenio (1999), de Antonio Gala ${ }^{18}$; o su Salve (2004), sobre la oración la-

La composición había obtenido el Premio de la IV Semana de Música Religiosa de Cuenca en 1965. Vid. GARCÍA LABORDA (2003): 205255.

8 Primer Premio del Servicio de Educación y Cultura, el Homenaje fue estrenado en el Festival de América y España en el Auditorio del Ministerio de Información y Turismo el 25 de mayo de 1965 por la Orquesta Nacional de España dirigida por Rafael Frühbeck de Burgos. Vid. SAN LLORENTE (2018): 202-203.

9 Estrenadas el 11 de marzo de 1970 en El café del Pintor Goya, recoge doce poemas albertianos, entre los que cabe destacar "El toro azul de Picasso", "Elegía del niño marinero", "La amante" o "Verte y no verte".

10 Esta primera colaboración con el poeta cordobés resultó de un encargo de la XVI Semana de Música Religiosa de Cuenca. Estrenada en la Iglesia de San Miguel, fue interpretada por el Grupo de cámara del Coro Nacional bajo la dirección de Sabas Calvillo y la Orquesta Filarmónica de Madrid, bajo la batuta de Isidoro Garcia Polo.

11 Resultado de un encargo de Radio Nacional de España para el Año Internacional del Niño, se estrenó en el Teatro Real de Madrid el 22.12.1979 bajo la dirección de Odón Alonso al frente de la Orquesta Sinfónica de Radiotelevisión Española, el mismo compositor como recitador; la soprano Norma Lerer y las Escolanías de Nuestra Señora del Recuerdo y de la Sagrada Familia dirigidas por César Sánchez.

12 Estrenadas en el Teatro Real de Madrid el 12.04.1984 por el tenor Joaquín Pixán y la Orquesta Sinfónica de Madrid dirigida por Jorge Rubio.

13 Dedicada a Montserrat Caballé, quien estrenó la obra bajo la dirección del propio compositor al frente de la Orquesta Nacional de España el 14.11.1990 en el Auditorio Nacional de Madrid.

14 Encargo de las Cortes de Aragón, el texto fue compuesto por la mano de varios autores -Ildefonso Manuel Gil, Ángel Guinda, Rosendo Tello y Manuel Vilas- y la obra fue estrenada bajo la dirección del propio compositor al frente de la Orquesta Sinfónica de Madrid el 23.04.1989, "Día de Aragón", en el Palacio de la Aljafería de Zaragoza, con la participación de tres corales provinciales (oscense, turolense y zaragozana).

15 Dedicadas a Teresa Berganza, fueron un encargo del Auditorio de Santiago de Compostela para el año Xacobeo de 1993. Estrenadas el 08.05.1993 por la soprano bajo la dirección del compositor al frente de la Orquesta Reina Sofía. Los poemas cantados fueron de Valle-Inclán, Álvaro Cunqueiro, Pedro Meogo, Francisco Añón Paz, Luis Pimentel, Sancho I, Mendiño, Celso Emilio Ferrero y Ramón Cabanillas.

16 Encargo del Orfeón Donostiarra para conmemorar el primer centenario de su fundación fue estrenada la Quincena Musical Donostiarra el 24.08.1997, en San Sebastián.

17 Estrenado en el Auditorio Padre Soler (Leganés, Madrid) de la Escuela Politécnica Superior de la Universidad Carlos III por el Coro y Orquesta de la propia universidad.

18 Estrenados por Rafael Frühbeck de Burgos al frente de la Orquesta Nacional de España en el Auditorio Nacional de Madrid el 28.12.1999. tina $^{19}$. Esta extensa línea genérica precedente nos lleva sin duda a pensar en el alcance y dimensión de la arriesgada decisión de proveerse a sí mismo de un poema de factura propia que articule su proceder compositivo ${ }^{20}$.

Cinco años más tarde, el título de la obra se erigió en razón fundamental para que fuera nuevamente programada en la temporada 2009-2010 de la Orquesta Nacional de España, una temporada concebida de modo temático en torno la Música y la Naturaleza, donde compartiría escena con obras donde el marco natural se convierte en matriz sonora: Los planetas de Holst; la Noche transfigurada de Schoenberg; la Sinfonía Alpina de Strauss; La consagración de la primavera, de Stravinsky; los Cuatro interludios marinos de Britten; la sinfonía "Renana" de Schumann; o la "Pastoral" de Beethoven"21. En sus notas al programa, Stefano Russomano contextualizaba con dudoso acierto la tendencia del compositor por propiciar títulos allí donde la naturaleza se hace de algún modo presente ${ }^{22}$, y recordaba la reflexión del primer crítico que glosara esta cantata, Andrés Ruiz Tarazona: "García Abril ha cantado y piensa seguir cantando a la obra magna de la naturaleza... El maestro se ha acercado en varias ocasiones a un mundo cosmógonico de estrellas, bóvedas celestes, constelaciones, espacios inmensos que exceden el alcance humano"23.

19 De marcado carácter personal, dedicada a la boda de su hija Adriana, fue estrenada por la Orquesta Filarmonía y el Orfeón Filarmónico con la soprano María Orán, el cellista Asier Polo y el organista Juan Manuel de los Ríos bajo la dirección de Pascual Osa el 03.07.2004 en la Iglesia madrileña de San Francisco de Borja.

20 Sestelo Longueira integra esta obra como la séptima de sus cantatas: Cantata a Siena (1955, fuera de catálogo); Cántico delle creature (1964); Cántico de "La Pietà" (1977); Alegrías (1979); Salmo de la alegría para el siglo XXI (1988) y Lurkantak (1997). Vid. SESTELO (2006): 1057.

21 Vid. PONS (2013): 126 y ss. y SUÑÉN (2013): 26 y ss.

22 "El catálogo de García Abril abunda en piezas cuyo título hace ya patente el motivo naturalista, aun cuando éste se mantiene entre los cauces de una evocación muy difusa. Cantos de pleamar, Alhambra, El mar de las calmas, Nocturnos de la Antequeruela, o colecciones como Canciones de noche y estrellas, Canciones de mar, amor y albas y Canciones de la floresta son tan sólo algunos ejemplos de esta tendencia", RUSSOMANO (2009): 5.

23 Ibídem. La obra fue interpretada junta a la Misa $n .^{\circ} 3$ en Fa menor de Anton Bruckner, bajo la dirección orquestal de Simone Young y de Mireia Barrera al frente del Coro Nacional de España. Recogemos aquí la crítica "Entre Antones" de Gonzalo Alonso: "Curioso programa el que reunió a dos Antones tan distintos, aunque con más cosas en común de lo que pueda parecer, como Antón García Abril y Anton Bruckner. Del primero, estrenándose la OCNE en él, el "Cántico de las siete estrellas" y del segundo la "Misa $n^{\circ} 3$ en Fa menor". Por tanto también un programa extenuante para el coro, que cumplió con notable. El maestro turolense siempre escribe con transparencia y delicadeza y este cántico, estrenado en 2004, vuelve a ser muestra de ello. También es autor que no deja a un lado el sentido comercial y la obra bien podía acabar siendo una especie de himno para la Comunidad de Madrid en algunos actos oficiales, no en vano se inspira en las siete estrellas de su escudo. El texto, del propio compositor, armoniza bien con una música. El coro, bien "a capella" o junto a la orquesta es protagonista fundamental de los momentos de intimismo, ya sea en su entrada o en 
En este sentido, uno podría pensar que la obra de Antón García abril se sitúa en la órbita del pensamiento que esbozan composiciones como Celestial Mechanics (Makrokosmos, 1979) de George Crumb (1929) $)^{24}$ - o Tierkreis-12 Melodien der Sternzeichen (1975-1976) de Karlheinz Stockhausen (1928$2007)^{25}$, claramente inspiradas por una visión cosmogónica del firmamento cuya reflexión se traduce en la técnica misma de la obra. Asistimos, sin embargo, en Cántico de las siete estrellas a un planteamiento poético de naturaleza extra-musical que busca sus asideros en la transformación, a través de la palabra articulada musicalmente, tanto de los fenómenos naturales observados como de un patrimonio histórico heredado y cristalizado no solo en formas iconográficas identitarias sino, fundamentalmente, en la estela del pensamiento propiciado por el humanismo español del XVI. Veamos este recorrido interpretativo.

\section{SIETE ESTRELLAS... GÉNESIS DEL TEXTO POÉTICO}

Antón García Abril actúa con "osadía”, tal y como él mismo confiesa, al escribir su propio texto para esta composición:

\section{Cántico de las siete estrellas}

Siete estrellas de la mágica constelación

que iluminan la noche.

Siete estrellas que dan luz al camino que

preludia el alba del día.

Constelación inspiradora y cercana,

rasgo infinito sobre bóvedas azules.

Geometrías deslumbradoras de movimientos eternos

y visión estática del cosmos.

Oración secreta del hombre.

Luz inextinguible, cegador espacio.

Áureos diseños cósmicos inseparables en la existencia invisible de su eternidad.

Estrella de las blancas cumbres que, desde su enigmática geografía,

aspira acariciar el cielo.

Estrella impulso del pensamiento universal.

\footnotetext{
"la oración secreta del hombre" y de las explosiones sonoras como la que acompaña a la frase "Luz inextinguible, cegador espacio". El final, una proclama a la unión de los pueblos y la vida, cierra la partitura en el mismo espíritu de serenidad inicial". ALONSO (2009), Beckmesser. Crítica. 29 de noviembre.

24 Makrokosmos, cuyo título alude al Mikrokosmos de Béla Bartók, se articula en cuatro volúmenes para piano compuestos entre 1972 y 1979. El primer y el segundo libro se centraron en los doce siglos zodiacales; el tercero tiene un claro componente poético, con epígrafes de Salvatore Quasimodo, Pascal y Rilke. El último libro, Celestial Mechanics, se estructura sobre cuatro piezas que convocan las estrellas Alpha Centauri, Beta Cygni, Gamma Draconis y Delta Orionis. Vid. VELESCU (2015): 93-98.

25 Compuesta originariamente para cajas de música bajo una concepción rítmica y melódica serial, cada signo zodiacal se centra sobre una de las alturas del espectro cromático, con desarrollos de duración vinculados a la serie de Fibonacci. Vid. KOHL (2012): 476-523.
}

Estrella del agua fluyente y vivificadora.

Estrella de los cauces que surcan nuestra tierra.

Estrella que proclama el amor y unión entre los pueblos.

Estrella que ilumina el pensamiento y fortalece las manos abiertas.

Estrella que eleva en incesante vuelo nuestros corazones.

Siete estrellas, misteriosa constelación cercana a nuestras vidas.

Impulso y energía desde su inmensa lejanía.

Constelación de las estrellas del amor.

Constelación de las estrellas de la paz.

Constelación de las estrellas de la unión entre los pueblos que proclaman la vida ${ }^{26}$.

La constelación de Osa Mayor está, efectivamente, formada por siete estrellas principales (Dubhe, Merak, Pechda, Megrez, Alioth, Mizar y Benethasch). Su naturaleza visible en el cielo la convierte en un equívoco referente para Ulises en su desesperado regreso a Ítaca (Homero, Odisea, V). La mitología griega señaló que fue Zeus, disfrazado de Artemisa, quien sedujo a Calisto -hija de Licaón, rey de la Arcadia, y ayudante de la hermana melliza de Apolo- la cual, a pesar de haber pronunciado su voto de castidad, engendró a Arcas tras aquel encuentro. Ovidio refiere que Calisto no murió entonces a manos de la airada Artemisa, sino que fue simplemente transformada en osa para que, años más tarde, cuando durante una cacería Arcas persiguiera a su propia madre sin reconocerla hasta el santuario de Zeus Liceo -allí donde ningún mortal debía jamás entrar-, Zeus subiera compasivamente a ambos hasta las estrellas como Osa Mayor y Osa Menor ${ }^{27}$. Esta conciliación final del conflicto hace de la bóveda celestial el espacio de encuentro armónico entre el pequeño mundo del hombre y la naturaleza superior, desarrollada no solo por el orfismo y el pitagorismo, sino por las culturas orientales que vieron en la misma Osa Mayor el motor del universo: cada una de sus siete estrellas, rsis o saptarsis, son identificados por los cuatro Vedas, los Bráhmanas o los Upanishad como los siete videntes cuyo aliento anima el movimiento de la creación ("Impulso y energía desde su inmensa lejanía") 28. Más adelante regresaremos sobre este aspecto.

Siete son, pues, las estrellas que coronan el escudo de la Villa de Madrid y que rotulan, finalmente, el pórtico de la cantata de Antón García Abril. Al privilegiar en su composición este elemento sobre los demás, el músico se sitúa en una estirpe exegética singular. Según Álvarez y Baena, "en el año 1212 no usaba Madrid otras Armas que un oso [...] Este tenía dentro de su cuerpo las siete Estrellas"29, pintado sobre azur y paciendo sobre un pasto verde. Francisco de Baztán Vergara asegura la

26 GARCÍA ABRIL (2006): I.

27 Las referencias aparecen en Ovidio, Las metamorfosis, II, 409; Eratóstenes, Catasterismos, I; Apolodoro, Biblioteca mitológica, III, 8, 2; e Higino, Fábulas, 177. Vid. DOMÍNGUEZ (2007): 27-64.

28 Vid. COOMARASWAMY (1977): 134

29 Vid. ÁLVAREZ Y BAENA (1786): 78. 
estrella Polar era la que estaba en la dirección de su rabo ${ }^{30}$. Esto ha confirmado en la heráldica la alusión a la constelación de Bootes (El Boyero), íntimamente ligada al mito de las dos Osas o del Carro. El mismo nombre de Carpetania o Carpetum, lugar de asiento de la ciudad, en latín quiere decir carro. La doble referencia a la Osa Mayor y Menor tendría, pues, una doble justificación que ilustraría sin duda el desconcierto confeso del crítico Antonio Iglesias: la primera se refiere al carro, y la segunda podría ser un indicativo de la gran calidad del cielo de Madrid, ya que no es fácil observar esta constelación. Este segundo caso encaja con la fama en astronomía que tuvo la ciudad durante el medievo por el nacimiento de Maslama al-Mayriti ${ }^{31}$. De hecho, fueron estas razones por las que, a mediados del siglo XVI, el príncipe Felipe, en nombre de Carlos I, concedió al Concejo madrileño el poder de incorporar la corona real y las estrellas a su escudo. Dicha concesión ocurrió en las cortes de 1548, y fue Juan Hurtado de Mendoza quien dio noticia del resultado en su Buen Plazer Trobado (1550):

"Soneto del autor a la misma Madrid por donde se dirige esta trova llamada Buen Plazer: y ofrece su musa al amor y vela en sus loores.

[...] Yo a vuestro el Madroño coronado

y fiera en siete estrellas figurada

miro con atención aficionada

en orla azul y campo plateado ${ }^{32}$.

En el libro de actas del Concejo de 09.04.1548 queda constancia que la razón de las estrellas de ocho puntas fue "por el cielo claro y extendido sobre Madrid", dado que recordaban las siete escuelas de astronomía existentes en época musulma$\mathrm{na}^{33}$. Juan López de Hoyos, quien fuera maestro de Cervantes, aventuró en 1569 la razón de sus siete estrellas como trasunto de la Osa Mayor:

Tienen las armas de Madrid por orla siete estrellas en campo azul, por las que vemos junto al Norte, que llamaban en griego Bootes, y en nuestro castellano, por atajar cosas y fábulas, llaman el carro, las cuales andan junto a la Ursa; y por ser las armas de Madrid Osa, tomó

30 Vid. BAZTÁN (1967): 34.

31 Vid. ÁVILA (2011): 54-65.

32 Juan Hurtado de Mendoza, Buen plazer trovado en treze discantes de quarta rima Castellana según imitación de trovas francesas [...], Alcalá, Ioan de Brocar, 1550, Biblioteca Nacional de España, R-12.874; en SÁNCHEZ ALONSO (1981): 4.

33 Vid. GUERRA (2010): 256. Sobre el escudo de Madrid y su compleja evolución consúltense los estudios de CASTRO PÉREZ DE CASTRO (2007):70-73; HUIDOBRO MOYA (2016): 32-36; y MATEO DEL PERAL (2011): 24-31. Sobre el cielo, "Es tierra muy templada y sitio excelente por la serenidad de su cielo. La maravillosa influencia del sol y concurso de los planetas influyen para que se encuentren en ella y sus contornos y murallas piedras, demás de los famosos pedernales [...]" Relaciones topográficas de los pueblos de España... (1575): tomo VII, J.I $18 \mathrm{f}$. $1 \mathrm{r}$. las mismas estrellas que junto a la Ursa, como hemos dicho andada, por razón de que, como en tiempo de Don Alfonso VI $[s i c]$, viniendo a ganar este reino de Toledo, el primer reino que ganaran fuera de Madrid, y para denotar que así como aquellas siete estrellas que andan alrededor del Norte son indicio de la revolución y del gobierno de los orbes celestiales, así Madrid, como Alcázar y Casa Real y primeramente que él, había de ser pueblo de donde los hombres conocieran el gobierno que para asistencia de los Reyes y señores de estos reinos de Madrid había de salir, y también porque este nombre Carpetano, que quiere decir Carro, por eso tomó las siete estrellas que en el cielo llamamos carro $^{34}$.

Esta interpretación se prolongó en el tiempo. Medio siglo después, con motivo del recibimiento de Mariana de Austria en la ciudad, se describe la construcción de cuatro arcos triunfales entre el Paseo del Prado y la Iglesia de Santa María. En el primero de ellos,

Estendíase el Pedestal de Madrid, en toda la longitud de su Quadro; retirandose primero a la parte opuesta á los lados, dexaba en medio, el espacio que, hablando con las Estrellas Osa, i Corona de su escudo, ocupó este Epigrama Castellano:

Dos Coronas, una Osa, i siete Estrellas

Mira España en las Armas de mi Escudo

En quien equivocarse el sol no dudo,

Viendo los Astros, que ilumina, en ellas:

Pues las estrellas siete, son aquellas,

Que el Carro forman a'1 Silencio mudo;

La Vrsa Mayor, la que ilustrarme pudo;

I las Coronas, de Ariadne bellas.

Con que, si el Carro, la Vrsa, y la Corona,

Imagines son mías, i d'el Cielo,

A quien ardiente el Solo dorar previene.

Bien del Cielo mi Fabrica blasona;

Pues nuevo Sol, en nuevo paralelo,

Carro Triunfal, Corona, i Vrsa tiene ${ }^{35}$.

Queda, pues, definido, el contexto genético de las palabras del Cántico de las siete estrellas. Detengámonos finalmente en el elemento singular de las fuentes, representado por el escudo madrileño desde sus momentos iniciales, y que constituye un destacado atributo de la villa que aparece descrito en Las relaciones topográficas de los pueblos de España (1575),

34 LÓPEZ DE HOYOS (1569): 4. El mismo texto es reproducido por Juan Diácono y Jaime Bleda en vida y Milagros del Glorioso S. Isidro el Labrador, Hijo, Abogado, y Patrón de la Real Villa de Madrid, Madrid, Tomas Iunti, 1622, en SÁNCHEZ Alonso (1981): 81.

35 Noticia del recibimiento i entrada de la Reyna nuestra Señora Doña Maria-Ana de Austria en la muy noble i leal coronada Villa de Madrid [s.1., s.a.] ca. 1650. Madrid, Biblioteca Municipal (MB-1.984); Biblioteca Nacional de España, R-31.757; 2-61.823, Mss. 11.205, $\mathrm{n}^{\circ}$ 1.; en SÁNCHEZ ALONSO (1981): 279. 
ordenadas por Felipe $\mathrm{II}^{36}$, con notable exhaustividad ${ }^{37}$. El mismo Juan Hurtado de Mendoza había aludido a sus aguas en un soneto dedicado a la divisa del escudo "cercada de fuego y armada sobre agua": "De fuego ser cercada te dixeron / antiguos siglos; y sobre agua armada: / tus venas de agua, y sierras luz te prestan" 38 . Esta es, sin duda, la razón fundamental de los versos "Estrella del agua fluyente y vivificadora / Estrella de los cauces que surcan nuestra tierra", tratados de un modo muy especial en la composición, según veremos.

Ahora bien, el movimiento de las estrellas -más allá de su cristalización heráldica- no solo explica la armonía cognoscible del cielo, sino que ordena el conocimiento del mismo y, en última instancia, los principios del gobierno moral. Nuestro compositor, en nada ajeno al mundo de la academia ${ }^{39}$, nos recuerda que en el saber medieval junto a las artes liberales del Trivium -Gramática, Dialéctica y Retórica-, Aritmética y Geometría convivían junto a la Astronomía y la Música en el Quadrivium $^{40}$. Tal y como con excelencia ha estudiado Luis Robledo en la Alegoría de las artes liberales del pintor barroco Miguel March (1633-1670), ambas artes manifestaban una

36 "Tiene dos escudos por armas: el uno consiste en dos eslabones que están golpeando un pedernal, con unas letras en medio que rodean el escudo y que dicen: Sic gloria, labore, y al fin, Paratur, con el siguiente epitafio: Soy sobre agua edificada, / Mis muros de fuego son, / Esta es mi insignia y blasón". Relaciones topográficas de los pueblos de España...(1575): tomo VII, J.I 18 f. 1r (Biblioteca de la Real Academia de la Historia, Ms. 9/5514).

37 "Tiene muchas y buenas fuentes, cuya agua es muy delicada. En el prado de San Jerónimo hay cinco fuentes de singular artificio, con su correspondiente bacía de piedra barroqueña, que tiene de diámetro diez pies y una vara de borde vaciadas por dentro y asentadas sobre un balaustre de cinco pies de alto; otro abrevadero con dos caños también de dicha piedra berroqueña, de largo 79 pies y de grueso más de 12: uno de los caños sale por la boca de un dragón, con un letrero que dice: Bueno, y el otro sale por la boca de una culebra, y a esta rodean otras dos arrebueltas, con una esfera que tiene un espejo de bronce y en el medio el siguiente letrero: Vida y gloria. A la mano derecha hay otra fuente de cinco caños, y a la mano izquierda otra de 50 caños, cuya agua al caer parece que está lloviendo. Más distante sale otra fuente con cuatro golpes de agua. También se ve otra fuente ochavada que mira a San Jerónimo con otros cuatro caños. Además de las citadas fuentes, procede recordar las de Leganitos, Lavapiés, los pilares viejos, las del Peral y de la Priora, en tanta abundancia que sobra agua para todo lo necesario; y esto sin la fuente tan experimentada de la salud llamada de San Isidro, cuyo cuerpo (del santo) está en la iglesia parroquial de San Andrés". Ibidem, f. 1v.

38 Juan Hurtado de Mendoza, Buen plazer trovado en treze discantes de quarta rima Castellana según imitación de trovas francesas [...], Alcalá, Ioan de Brocar, 1550, Biblioteca Nacional de España, R-12.874, fol. 38v; en SÁNCHEZ ALONSO (1981): 5.

39 Recordemos que el 02.06.2003 Antón García Abril fue investido Doctor Honoris Causa por la Universidad Complutense de Madrid junto a Teresa Berganza y el historiador británico John Elliot. Vid. PALACIOS (2003): 453-468.

40 Remitimos aquí a la famosa representación de los saberes en el Hortus Deliciarum, manuscrito ilustrado medieval del convento de Mont Sainte-Odile Abbey -hoy perdido- y que fue una de las primeras fuentes de polifonía conventual en Europa. Vid. PHELAN (2017): 60-75. estrecha complicidad ${ }^{41}$ en la configuración del saber más alto, bien el teológico, bien el filosófico. Concebido el carro de la constelación, como señalamos más arriba, como aliento del firmamento -"Impulso y energía desde su inmensa lejanía” en el poema de García Abril-, no debe sorprendernos que las siete artes liberales fueran representadas en ese mismo carro como vértices visibles del conocimiento, tal y como nos ha llegado en una ilustración del siglo XV depositada en la Biblioteca de la Universidad de Salzburgo, donde se ve al teólogo y obispo Pedro Lombardo conducir este carro astronómico emblema de un saber transcendente manifiesto en los versos centrales de la cantata: "Estrella impulso del pensamiento universal [...] Estrella que ilumina el pensamiento".

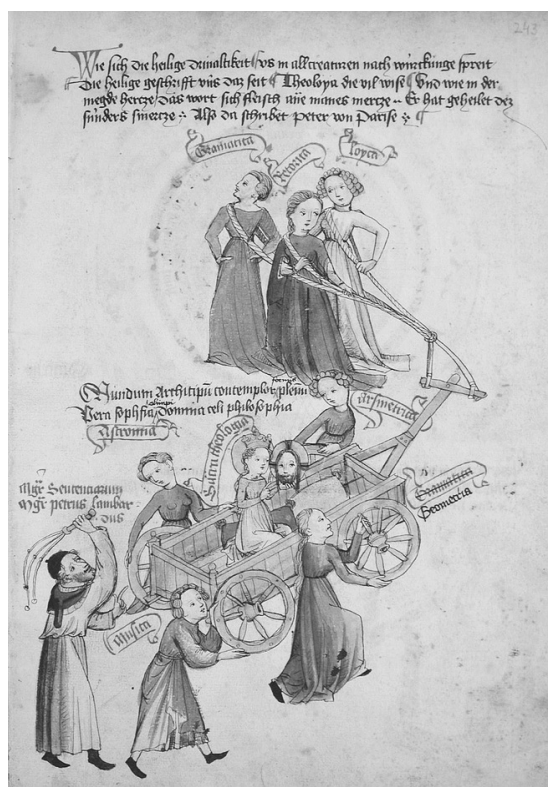

Fig. 1. Artes liberales. Unibibliotek Salzburg, M. III 36, fol. 243r

El texto de nuestro compositor se suma así a una larga tradición que recoge Alfonso X en español por vez primera en el Setenario, donde bien desde Avicena, bien desde Dionisio

41 “Astronomía interpela con la mirada al astrónomo y le señala con la mano izquierda lo que hace Música, mientras con el cetro de su mano derecha apunta hacia lo alto, como queriéndole decir «Atiende, lo que tú buscas con tu arte se halla aquí, en la música; la fábrica celeste que tu estudias, los movimientos de sus cuerpos se resuelven en música, en una música superior que es la suprema armonía de la que es reflejo esta armonía que suena junto a ti». Parece claro que Astronomía está recordando al astrónomo, a nosotros, espectadores, que el principio del universo descansa en la armonía, una armonía que garantizan las proporciones aritmético-musicales y que se manifiesta en la música de las esferas. Miguel March nos está recordando que el origen del mundo es la armonía musical primigenia transmitida por la tradición pitagóricoplatónica”. ROBLEDO (2012): 36. Sobre las relaciones Astronomía y Música, vid. JOU (2003): 33-40. 
Areopagita, el cosmos se sucede sin solución de continuidad entre sus partes, como un todo coherente al que se accede por saberes jerarquizados y donde la música es puente esencial entre la bóveda celeste y del microcosmos del hombre:

et ésta, comoquier que los homnes usen della en sones e en cantares e en estrumentos, tal es en sí que en todas las cosas cae e sin ella no se podría fazer, porque compone e acuerda todo [...] es contenente, que conviene mucho que se faga en la música, para acordarse la manera del homne con el son" ${ }^{42}$.

Esta mirada hacia el cielo que eleva Antón García Abril encuentra la de Fray Luis de León, quien en su oda "A Felipe Ruiz” -“¿Quando será que pueda / libre desta prisión volar al cielo?", bastante menos conocida que la dedicada a Francisco Salinas-, trata de ascender hacia la contemplación de los fenómenos naturales - de esta "mágica constelación", en su referencia expresa a las dos Osas (Mayor y Menor)- con el fin de alcanzar la comprensión intelectual que le acerque a la visión divina desde la matriz nocturna de su humanidad:

Quién rige las estrellas

veré, y quién las enciende con hermosas

y eficaces centellas;

por qué están las dos Osas

de bañarse en el mar siempre medrosas ${ }^{43}$.

El texto musical, en consecuencia, se inicia con esa mirada al firmamento y asciende así como mediador hacia un cumplimiento de plenitud moral y de reconciliación con la ley eterna - "Áureos diseños cósmicos inseparables en la existencia invisible de su eternidad"-, el principio imperecedero que el propio Fray Luis glosa en su Exposición del libro de Job:

Porque en el ser que dio a las criaturas y en la manera como las ordenó y en la ley que les puso nos enseñó que nuestro bien y saber verdadero consiste en reconocer su ley y cumplirla. Que si crio a todas las demás cosas con orden, y si las compuso entre sí con admirable harmonía, no dejó al hombre sin concierto, ni quiso que viviese sin ley, ni que hiciese disonancia en su música ${ }^{44}$.

El hombre que mira hacia lo alto, tal y como nos propone compositor de Divinas palabras, distingue en definitiva un modelo definitivo de paz y concordia que debe regir su propio yo en la convivencia social del pueblo: "Estrella que proclama el amor y unión entre los pueblos / [...] Constelación de las estrellas de la paz". Una expresión sintética de la lectura agustiniana de la que el propio Fray Luis se hace eco en De los nombre de Cristo:

42 ALFONSO X (ed. 1984): 34.

43 FRAY LUIS DE LEÓN (ed. 1990): 272. Vid. también en Góngora la velada cita a las Osas Mayor y Menor en su Soledad Primera en ARELLANO (2014): 201-233.

44 FRAY LUIS DE LEÓN (ed. 1944): 1150.
[...] cuán amable cosa sea la paz, esta vista hermosa del cielo que se nos descubre ahora y el concierto que tienen entre sí aquestos resplandores que lucen en él nos dan de ello suficiente testimonio. Porque ¿qué otra cosa es sino paz -o ciertamente una imagen perfecta de la paz- esto que ahora vemos en el cielo y que con tanto deleite se nos viene a los ojos? Que si la paz es, como San Agustín breve y verdaderamente concluye, «una orden sosegada», o un tener sosiego y firmeza en lo que pide el buen orden eso mismo es lo que nos descubre ahora esta imagen [...] Porque luego, como convencidas [se refiere a las almas] de cuánto les es útil y hermosa la paz, se comienzan ellas a pacificar en sí mismas ya poner cada una de sus partes en orden $[\ldots]^{45}$.

Cántico de las siete estrellas surge, pues, como "Oración secreta del hombre" en la contemplación de esa otra música inteligible que de la mano de Salinas se "viste de hermosura y luz no usada", transformando la mirada en sonido reflejo del cielo musical contemplado: "Constelación inspiradora y cercana, / rasgo infinito sobre bóvedas azules"; "Siete estrellas, misteriosa constelación cercana a nuestras vidas". Antón García Abril inicia su canto, en consecuencia, como una paráfrasis de los versos iniciales de la Noche serena del poeta agustino - "Cuando contemplo el cielo / de innumerables luces adornado" 46 . El movimiento de los astros expresado así por el compositor -"Geometrías deslumbradoras de movimientos eternos y visión estática del cosmos"trasciende todo tiempo y se instala en la mirada del discreto fraile belmonteño, que requiere del firmamento esa ley universal:

de aquestos resplandores terrenales, su movimiento cierto, sus pasos desiguales

y en proporción acordes tan iguales $[\ldots]^{47}$.

Un encuentro con la "Constelación de las estrellas del amor" -"graciosa estrella / de amor" en Fray Luis ${ }^{48}$, amor que según San Pablo "nunca deja de ser" (I, Corintios, 13, 8)- y que en el texto del Cántico de las siete estrellas no es sino "Estrella que eleva en incesante vuelo nuestros corazones", en un nuevo pensamiento que asciende como una glosa del humanista salmantino en sus comentarios al Libro de Job,

Llama música de los cielos a las noches puras, porque con el callar en ellas los bullicios del día y con la pausa

45 FRAY LUIS DE LEÓN (ed. 1944): 598. En De los nombres de Cristo se nos dice: "Como la cuerda en la música, debidamente templada en sí misma, hace música duce con todas las demás cuerdas sin disonar con ninguna, así el ánimo concertado dentro de sí y que vive sin alboroto tiene siempre en la mano la rienda de sus pasiones y de todo lo que en él puede mover inquietud y bullicio, consuena con Dios y dice bien con los hombres y, teniendo paz consigo mismo, la tiene con los demás”. FRAY LUIS DE LEÓN (ed. 1944): 607.

46 FRAY LUIS DE LEÓN (ed. 1990): 475.

47 FRAY LUIS DE LEÓN (ed. 1990): 475.

48 FRAY LUIS DE LEÓN (ed. 1990): 475. 
que entonces todas las cosas hacen, se echa claramente de ver y en una cierta manera se oye su concierto y harmonía admirable, y no sé en qué modo suena en lo secreto del corazón su concierto que el compone y sosiega [subrayado nuestro] $]^{49}$.

Antón García Abril, en definitiva, no solo construye los andamios textuales de su obra sobre la tradición heráldica consagrada en el escudo de la Villa, sino que incardina cada uno de sus versos en la corriente ascética de la segunda mitad del siglo XVI, en una clara recuperación del pensamiento humanista que en tantas ocasiones ha reivindicado tanto en su dimensión ética como intelectual $^{50}$. Una tradición que aspira a ubicar al hombre en armonía con la creación y que coronaría el Fénix de los ingenios, la voz poética por excelencia del Madrid áureo, quien en Los locos de Valencia proclama sin embozo la unidad con el cosmos del hombre que indaga en la bóveda celeste las fuentes del conocimiento último y verdadero.

La música es divina concordancia deste mundo inferior y del angélico. Todo cuanto hay en todo, todo es música; música el hombre, el cielo, el sol, la luna, los planetas, los signos, las estrellas; música la hermosura de las cosas; ut, sol, fa, sol, re, mi, fa, sol, re, $u t^{51}$.

\section{"UNIÓN ENTRE LOS PUEBLOS QUE PROCLAMAN LA VIDA": LA MÚSICA COMO CAUCE DEL DOLOR COMUNITARIO}

Desde los atentados del 11.09.2001 en Estados Unidos y los acaecidos en Europa con desgarradora violencia en nuestro país el 11.03.2004, las artes han ocupado un relevante espacio reparador como respuesta personal y social, pacífica y cauterizadora del dolor provocado por un desprecio a la vida cuyo valor se relativiza y se reduce al mero dominio ideológico ${ }^{52}$. Recor-

49 FRAY LUIS DE LEÓN (1944): 1280.

50 En la entrevista realizada por Ruth Prieto publicada en el blog El compositor habla el 21.01.2016, nuestro autor responde así ante la siguiente pregunta: "Ruth Prieto: Desde sus primeras obras hasta este último estreno ¿cómo ha evolucionado García Abril? ¿Qué queda, qué ha cambiado? Antón García Abril: La evolución propia y natural del ser humano en su travesía por los cortos - largos caminos de la vida de la cultura, del arte y del humanismo. En cuanto a los principios básicos del arte musical me he mantenido siempre partiendo de la idea de que la música conlleva un lenguaje de comunicación. Este postulado me exige la búsqueda de un doble compromiso, lograr una excitación intelectual, a la vez que una comunión estética" Vid. http://www.elcompositorhabla. com/es/noticias.zhtm?arg_id=366 [consultado el 20 de marzo de 2018]. 297-310

51 DE VEGA (ed. 2003): vv. 2489-2495. Vid. PASTOR (1998):

52 Consúltense en este sentido los trabajos de GANGI \& BARWOSKY (2009): 357-363; COULTER-SMITH (2009), MARAZUELA (2016):107-110; PUTNAM (2009): 595-606, RITTER \& DAUGHTRY (2012) y ZYDOROWICZ (2010): 201-217. demos, por un lado, que la obra de García Abril ha venerado en distintas ocasiones la memoria de las víctimas del terrorismo ${ }^{53}$. La decisión de dedicar Cántico de las siete estrellas a todas las víctimas del 11-M transforma de un modo inesperado la génesis del texto, dado que activa la mediación reparadora de la música ante una brutal desposesión que dejó aturdida y conmovida a toda la sociedad española. La literatura respondió con las obras de Blanca Riestra, Adolfo García Ortega o Luis Mateo Díez ${ }^{54}$; la arquitectura diseñó memoriales, puntales y espacios abiertos que adoptaron el nombre de la tragedia ${ }^{55}$; el humor gráfico consoló con inusitada ternura en la pluma del genial Forges en el diario El Pais ${ }^{56}$; la exposición Arte solidario, organizada por la Comunidad de Madrid en el complejo El Águila de Madrid del 12 de marzo al 22.05.2005, supuso una iniciativa colectiva concebida como un tren de la memoria en el que participaron Gordillo, Canogar, Castro Prieto, Genovés, Patiño, Torres, Guinovart, Schommer, Corazón, Amat, García Rodero o Toral entre otros y comisariada por Valeriano Bozal y Javier Tusell ${ }^{57}$. La música ligera ha dejado en la memoria el tributo de grupos como La oreja de Van Gogh ("Jueves", del álbum A las cinco en el Astoria, Sony, 2008), Marcos Vidal y Antonio Carmona ("Margerit", para el documental Todos íbamos en ese tren, Docus, 2004); Luz Casal ("Ecos", en su disco Alegría sencilla, Epic Records, 2004) o Ismael Serrano ("Fragilidad" en Naves ardiendo más allá de Orión, Universal Music, 2005) ${ }^{58}$. En el

53 Sus Canciones de Valldemosa, sobre poemas de Antonio Gala, fueron así interpretadas en el concierto que Ainhoa Arteta y Macolm Martineau ofrecieron en el Auditorio Nacional el 21.02.2015 como Homenaje al Profesor Tomás y Valiente. Músicas por la Paz, dentro del XLII Ciclo de Grandes Autores e Intérpretes de la música de la Universidad Autónoma de Madrid, junto a obras de Reynaldo Hahn, Isaac Albéniz, Manuel de Falla, Miquel Ortega, Enrique Granados y Fernando Obradors. PÉREZ DE ARTEAGA (2015): 3.

54 Nos referimos a los libros de Blanca Riestra, Madrid Blues (Madrid, Alianza Editorial, 2008), Adolfo García Ortega, El mapa de la vida (Barcelona, Seix Barral, 2009), y Luis Mateo Díez, La piedra en el corazón (Madrid, Galaxia Gutenberg, 2006).

55 Recordemos aquí el Jardín de los Ausentes en el parque del Retiro; la plaza monumento de El Pozo, que combina arquitectura y pintura en una serie de cuadros que adoptan las ventanillas de un vagón de tren; el rascacielos residencial más alto de Europa, In tempo, en Benidorm, cuyas dos torres de 200 metros emulan un 11 enfrentado; o el Monumento a las Víctimas del 11-M, cuya cúpula cilíndrica de 11 metros de altura fue proyectada por los arquitectos Esaú Acosta y Gil-Fournier. 56 Recordemos entre otras muchas las ilustraciones de Ricardo Cámara en Interviú; Puebla en $A B C$, Zulet en El Correo de Bilbao; Jose Julio en Europa Press, o Malagón en el Diario de Alcalá.

57 Otra exposición solidaria, $11 \mathrm{M}$. Testimonios del arte, tuvo lugar en la galería Áurea-Centro de Arte, en Madrid (Benigno Soto, 12, hasta el 9 de abril de 2005), organizada por la Asociación de Pintores Realistas de Madrid, con un proyecto de la pintora Alejandra Osado, en el que participaron 50 artistas, profesionales y estudiantes de Bellas Artes.

58 La relación, indudablemente, es mucho más amplia. Recordemos simplemente aquí los nombres de Gontzal Mendibil (Lágrimas al viento, con la Orquesta Sinfónica de Bratislava y el Orfeón Donostiarra, KEINU, 2004); Fito Páez, Pablo Milanés, Javier Gurruchaga y 
ámbito de la música destinada a la sala de conciertos, merece ser destacada la obra de Pilar Jurado Stabat mater, encargo de la XLIV Semana de Música Religiosa de Cuenca en el año 2005, quien, junto al texto latino, introdujo palabras de Pilar Manjón, presidenta de la Asociación 11-M Afectados del terrorismo. La propia autora subrayó el lugar que el dolor ocupaba en la experiencia adquirida y dispuesta en esta composición:

No quería poner música a un texto sin más, sobre todo dadas las circunstancias y el momento que estábamos viviendo $[\ldots]$ hemos sido testigos de una guerra como la de Irak, de muchas madres que sufren en Afganistán, en Palestina, de muchas mujeres maltratadas... Estamos viviendo un momento social en el que la mujer desempeña el papel de madre dolorosa mucho más que el hombre y además lo lleva en silencio. En mi condición de mujer pensé que debía tener una actitud comprometida y por eso quería dedicarles a ellas esta obra ${ }^{59}$.

Singular predicación ha tenido la obra Da pacem domine de Arvo Pärt, comisionada por Jordi Savall para el concierto celebrativo de la paz en Barcelona, el 1 de julio de 2004, y que cada año es interpretada ante el monumento erigido en la estación de Atocha. El texto latino se sostiene sobre versos bíblicos ${ }^{60} \mathrm{y}$, si bien fue escrita originariamente a cuatro voces, en el año 2007 experimentó una ampliación para coro mixto y orquesta de cuerda celebrada por la crítica ${ }^{61}$.

Este contexto nos describe sin duda el espacio dentro de un proceso de reparación del dolor que la obra de Antón García Abril ocupa. Por un lado, debemos recordar que no es la única obra de nuestro autor que se rinde a la memoria de las víctimas del brutal atentado. Coetánea a Cántico de las siete estrellas es

Ana Belén, pusieron, entre otros, sus voces en el disco No os olvidamos (Sony, 2005). Otros homenajes lo realizaron El Chivi ("Trenes para el cielo", No-Album, 2004), Kannon ("Chaval", Intro, 2004), Habeas Corpus ("11 de marzo", pista en blanco de un minuto de silencio en su disco Armamente, Propaganda Pel Fet!, 2004); grupos de hip-hop tales como Baco, L.E. Flac, Zenit, Artes 1-29, Doblehace que unieron para cantar en torno al 11 de marzo, en el 2004; Arma Blanca ("El último tren", Autodidactas, 2007 ), o el disco colectivo de hip-hop Un año de reflexión (2005).

59 Entrevista recogida por GAVIÑA (2005): 81.

60 Las fuentes se sitúan en el Reyes II, 20:19; Crónicas II, 20:12 y 15; Salmos, 73:6-7. La obra fue grabada por vez primera el 29 de marzo de 2005 por el Hilliard Ensemble, en Saint Gerold, Austria y grabada en por la Estonian Philharmonic Chamber Choir, bajo la dirección de Paul Hillier; Kaia Urb, soprano; Christopher Bowers-Broadben, órgano (Harmonia Mundi France HMU 907401). Para el crítico musical Allan KOZINN "On the surface these are slow-moving, meditative scores. Da Pacem Domine (2004), a prayer for peace, is cast in sustained tones with little harmonic growth and hardly any momentum, yet a listener is drawn inexorably into its hypnotic four-part unaccompanied vocal texture". The New York Times (08.10.2006).

61 Esta versión fue estrenada en Tallín el 18 de mayo de 2017 bajo la dirección de Tönu Kakjuste. Para la edición orquestal vid.PÄRT (2006). la obra El bosque de los ausentes, composición que pasaría más tarde a ser el segundo movimiento de la Sonata de Atardeceres escrita para violonchelo y piano ${ }^{62}$. Esta breve pieza se integró entonces dentro de la obra Once voces contra la barbarie del 11$M$, un proyecto teatral colectivo coordinado por Adolfo Simón que aglutinó piezas breves de once dramaturgos y que fueron representadas en distintos teatros madrileños en el primer aniversario de la perpetración del atentado ${ }^{63}$. En su estreno, nuestro compositor expresa que esta propuesta "no tiene nada de exhibición y tiene mucho de oración, de amor" ${ }^{64}$. El bosque de los ausentes nació, pues, con una clara vocación intimista como asunción personal de un dolor colectivo, y la música emerge como consuelo ante el desgarro, aunque después evolucione hacia la forma abstracta de un movimiento de sonata. Por el contrario, Cántico de las siete estrellas surge de una dimensión primigenia colectiva -el pueblo de Madrid-, y será el contexto -dentro del esquema comunicativo que Jakobson propone- quien determine y transforme las condiciones de su recepción y las atribuciones posibles de significado tras el brutal atentado del 2004. En un día tristísimo que hubiera renunciado a su propio amanecer, ese 11 de marzo el sol rompía el alba a las 7:32 de la mañana ("Siete estrellas de la mágica constelación que ilumina la noche. / Siete estrellas que dan luz al camino que preludia el alba del día" ${ }^{65}$. Apenas cuatro minutos después se produjeron diez explosiones casi simultáneas en cuatro trenes de Madrid. La respuesta que concluye el tránsito musical y colectivo que nos propone Antón García Abril cauteriza el dolor de la bárbara amputación, la pérdida irracional y definitiva que conmovió al mundo entero, a través de la celebración sobre la muerte: "Constelación de las estrellas de la unión entre los pueblos que proclaman la vida”.

\section{ANÁLISIS MUSICAL}

Veamos finalmente en el análisis de la estructura musical cómo articula Antón García Abril su texto ${ }^{66}$. La obra, tal y

62 Vid. CORONA (2008): 348-349. La Sonata de atardeceres para cello y piano fue editada en Madrid, Bolamar Ediciones Musicales, 2009. El movimiento lento fue inicialmente grabado por Asier Polo en el violonchelo y con el mismo García Abril al piano. El nombre de la sonata recuerda sin duda a otra forma autónoma, el Concierto de las tierras altas, cuya reducción para cello y piano fue editada en Madrid, Bolamar Ediciones Musicales, 2002.

63 Teatro de La Abadía, Teatro Pavón, Centro Dramático Nacional, Círculo de Bellas Artes, Casa de América y Sala Cuarta Pared. Los autores fueron Ignacio Amestoy, Ana Diosdado, Yolanda Dorado, Raúl Hernández Garrido, Juan Alberto López, Jerónimo López Mozo, Yolanda Pallín, Paloma Pedrero, Margarita Reiz, Laila Ripoll y Julio Salvatierra. Vid. AA.VV. (2006), que incluye la partitura de Antón García Abril. Un estudio profundo sobre este proyecto puede consultarse en LÓPEZ SÁNCHEZ (2011):101-118.

64 TORRES, Diario El País (10.03.2005).

65 Datos tomados del Observatorio Astronómico Nacional, Instituto Geográfico Nacional, del Ministerio de Fomento (http://www.fomento.gob.es/salidapuestasol/2004/Madrid-2004.txt).

66 Recordemos la amplia paleta orquestal de la obra: 2 flautas ( $2^{\circ}$ con flautín); 2 oboes ( $2^{\circ}$ corno inglés); 2 clarinetes $\left(2^{\circ}\right.$ con clarinete 
como puede verse en la tabla adjunta, se dispone en dos grandes secciones desiguales, -divididas en siete subsecciones cada una- separadas por una sección central -cc. 170-201- que subrayará tres versos esenciales: "Estrella impulso del pensamiento universal. / Estrella del agua fluyente y vivificadora. / Estrella de los cauces que surcan nuestra tierra". Una breve introducción instrumental (1) en la cuerda de naturaleza impresionista (cc. 1-30) inicia y regresa el discurso a $L a M 7$-veremos que las sucesiones de séptimas tienen un papel esencial- a través de un descenso cromático lineal descendente. El verso inicial "Siete estrellas" (2) rompe estática y extáticamente el silencio de cesura a capella, con madrigalismos sobre la palabra "noche" -semitono cromático descendente, enunciado doblemente como un lejano eco. El uso de la anáfora "Siete estrellas" -interrumpido por la violenta, casi profética, incursión del látigo y bombo (c. 38)- conducirá a un gesto cadencial -acordes de séptima de dominante de $D \circ \# M$ y $F a \# M$ - sobre las palabras "al alba del día", tras el cual flautín, flauta y vibráfono en tresillos sobre intervalos de tercera menor $-\mathrm{Do} / \mathrm{Mi}$ b; $\mathrm{La} / \mathrm{Do}-$, segunda menor - La/Sol\#- y cuarta justa - Sol\#/Re\# evocan los trinos de las aves en la aurora (c. 43). Inmediatamente después se inicia una descomposición textual del verso -cc. 44-56-, sobre la célula melódica de la introducción y los arpegios sincopados ascendentes y descendentes de los violonchelos. El estilo nominal del poema se fragmenta alterando la sintaxis - "el alba del día, camino, la noche, preludia..."- en saltos interválicos cada vez más pequeños (de sexta menor, c. 45; cuarta justa, c. 47; tercera menor, c. 49), de un modo que volverá a aparecer en el eje central de la obra. En un discurso armónico en el que se suceden acordes de séptima de dominante -de segunda inversión a estado fundamental sobre ReM, FaM, La bM, Re bM, $M i b M, F a \# M, \operatorname{Re} b M$ - la música se conduce al II grado rebajado -“día”, en DoM, que emerge como una sonoridad triádica limpia antes no presente- y cadencia a través de su dominante sobre SiM como novena de dominante. Sobre el gesto melódico de la introducción y en la alternancia del movimiento dominante/ tónica se aceleran los valores rítmicos -tresillos de negra, c. 57; tresillos de corchea, c. 58- para alcanzar la estabilidad de $M i M$, cuyo pedal es emborronado armónicamente en los vibráfonos por las disonancias mayor/menor -cromatismos Sol\#/Sol y Re\#/ Re. Se llega así a la siguiente sección -cc. 68-106- "Constelación inspiradora y cercana [...] (3), donde la posición estrecha de las voces enfatiza esa cercanía y se amplía el compás de 4/4 a 5/4 sobre la palabra "infinito", cuya última sílaba se extiende sobre una quinta en vacío $-\mathrm{Mi} / \mathrm{Si}$ - durante siete largos pulsos. El término "bóvedas" es enunciado sobre el intervalo armónico del tritono (ReM/LabM, c. 77); los violines refuerzan el sentido de altura con saltos de séptimas (c. 78) y la transición armónica se hace sobre el encadenamiento de acordes de séptima de

bajo); 2 fagotes ( $2^{\circ}$ con contrafagot); 2 trompas; 3 percusión (2 vibráfonos, campanas budistas, látigo, bombo, marimba, timbal, caja, tamtam, plato suspendido, lira); piano, arpa, cuerda y coro mixto. La obra dura unos veinte minutos. dominante por terceras $-M i M / D o M$; ReM/SibM (cc. 79-85)-, enlace armónico constante en la composición" ${ }^{67}$. Las "geometrías deslumbradoras" son desarrolladas tímbricamente por xilófono, vibráfono y marimba con diseños geométricos bimembres -esquema rítmico-melódico de ocho semicorcheas (4+4) duplicado en el compás (cc. 87-89)-; "movimientos eternos" se enuncian en el acorde de séptima de dominante de $M i b M$ sobre largas notas repetidas y una nueva ampliación de 4/4 a 5/4; y la conciliación del microcosmos con el macrocosmos - "y visión estática del cosmos. / Oración secreta del hombre"-, es enunciada a capella, desde el movimiento mínimo de las voces, esta vez sobre nuevas sonoridades armónicas, los acordes de séptima de sensible sobre Sol\#, Si, Fa\# y La-cc. 91-95. Concluye esta sección el canto del oboe y un juego de imitación final en oboe, violín, viola y cello, en un contexto armónico que discurre nuevamente por el encadenamiento por terceras de acordes de séptima de dominante (FaM/ReM; SolM/MiM; LaM/Fa\#M; ReM/Si bM; Mi bM/DoM, cc. 96-105).

La siguiente sección, "Luz inextinguible [...]" (4), se enuncia sobre un largo pedal -acorde de séptima de dominante de $D o M$ - en un canon con desdoblamiento de voces bicinias con cierto sabor arcaico -en intervalos de cuarta entre soprano y alto, cc. 107-111- rematado por su expresión homofónica-cc. 120-124- que cadencia en el acorde de séptima de dominante de FaM. Un silencio con calderón inicia la siguiente sección "Áureos diseños cósmicos [...]" (5), en una mixtura armónica de SiM y Si bM animada de nuevo tímbricamente por vibráfonos, marimba, arpa, piano y celesta. Esta superposición armónica se transmite al texto, donde "áureos diseños" e "inseparables" se pronuncian conjuntamente; los violines se extienden hacia las alturas más agudas -casi como remotos sonidos armónicos- y la palabra "eternidad" se articula largamente sobre la expresión de un absoluto DoM (cc. 120-139). Comienza así un interludio instrumental (cc. 140-160, sección 6), emparentado con la melodía precedente entonada por el oboe en los cc. 95-10768, de naturaleza cromática sobre una convencional sucesión armónica de quintas descendentes - tal vez como descenso de lo contemplado hacia el contemplador-, que dará paso a la relación de las siete estrellas invocadas. "Estrella de las blancas cumbres" (sección 7, cc. 161-169), presenta dobles saltos de séptima paralelos en piano, vibráfono y celesta, así como saltos de octava disminuida -séptimas menores- que acentúan en el tiempo las disonancias armónicas de segunda menor que se dan entre tenor

67 Sobre este recurso, vid. BRIBITZER-STULL (2006): 167190.

68 Sobre el valor de la melodía en Antón García Abril y su ampliación al concepto de "polimelodiosidad" vid. FERNÁNDEZ DE LA CUESTA (2003): 195-204 y SORIA (2016). Distintos lugares de la obra recogen esta singular concepción neorromántica que integra ritmo, forma y textura en un contexto tonal extendido. Sucede así en los compases de la introducción (cc. 1-31), y en buena parte de las secciones instrumentales que anteceden la entrada del coro (cc. 96-106; cc. 140-160; cc. 240-253; cc. 265-276), cuyo análisis detenido excedería los límites de este trabajo. 
y soprano sobre la palabra "cumbres" (c. 163). Sorprende el enlace armónico de tercera menor, Mi bM/Fa\#m, por primera vez presente en la obra, sobre la palabra "enigmática" (c. 165), así

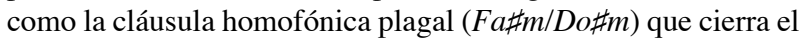
verso "acariciar el cielo" (cc. 168-169).

Concluye así esta primera gran parte de siete subsecciones y se inicia una eje central (8), más animado-Più mosso- sobre tres versos capitales en la obra: "Estrella impulso del pensamiento universal. / Estrella del agua fluyente y vivificadora. / Estrella de los cauces que surcan nuestra tierra". La palabra "impulso" tendrá aquí un cierto tratamiento polifónico que subraya su naturaleza dinámica -c. 176- y las figuraciones en tresillos de los violines segundos, junto a las articuladas por los vibráfonos, piano, celesta y arpa, contribuyen a expresar el sema "fluyente" cc.179-181. Tal y como sucediera en los cc. 44-56, el compositor vuelve nuevamente a descomponer los versos -“cauces, / surcos, / aguas fluyentes y vivificadoras, / fluyente, / cauces, / surcos, / nuestra tierra, / vivificadora, / el surco / de los cauces / del agua fluyente y vivificadora" sobre enlaces armónicos esencialmente de tercera para cadenciar en un acorde de novena de dominante con oncena agregada en la palabra "vivificadora", donde se alcanza el máximo melódico $-L a_{5}-$ de toda la obra por un mayor tiempo hasta entonces -cinco pulsos, c. 195. Debemos destacar aquí que esta altura que aparece brevemente en otras palabras de un alto valor semántico -“alba” (negra, c. 56), "espacio” (negra, c. 124), "corazones" (semicorchea, c. 239)-, solo volverá surgirá en una larga expresión estática sobre el acorde tríada que inaugura la cantata, LaM, en la palabra "vida" (cc. 290-294), antes de la doble coda final. Existe, en consecuencia, una lógica semántica en la distribución de alturas que afecta, además, a la estructura o "geometría" de la composición: dividida su extensión por la sección áurea, ese punto de máxima tensión se anticipa con claridad, precisamente, en ese momento esencial -matemático, áureo y universal- de la obra, encuentro "vivificador" de la razón con la totalidad invocada por el cántico.

Concluida esta sección central, se inicia una segunda parte, algo más breve, dividida nuevamente en siete subsecciones. La primera de ellas - "Estrella que proclama el amor entre los pueblos" (9, cc. 202-220) comienza con la presentación instrumental sobre un largo pedal en $D o M$ de un rápido gesto quiasmático, casi universal -Re b-Mi b-Si b-Do-, que conduce a una lánguida conducción de la cuerda, cromática y descendente, tras la palabra "amor". "Estrella que ilumina el pensamiento" (10, cc. 220-232) se desarrolla de un modo contrapuntístico -intelectual- sobre el gesto quiasmático previamente esbozado $-\mathrm{y}$ presente con ampliación de valores en los compases instrumentales que cierran el verso-, con el desdoblamiento de las voces masculinas en "fortalece" y el recuerdo (c. 221) de las campanas budistas de la introducción (cc. 29-30). "Estrella que eleva en incesante vuelo nuestros corazones" (10, cc. 232-253) es comentado por el pálpito del timbal y el ostinato sobre $L a b$ en las cuerdas graves (cc. 249-253) tras glosar los violines el gesto melódico expresado en "corazones" (cc. 240-249). Este ostinato rítmico es alterado -sincopado y a contratiempo-para introducir "Siete estrellas, misteriosa constelación [...]" (12, cc. 253-264) de un modo contrapuntístico contrastante con la enunciación de "cercana" en estilo homofónico. En apenas seis compases (cc. 259-264) la escritura evoluciona hacia tonalidades enarmónicas -Sol bM / Fa \#M- fundiendo así los dos antónimos semánticos pronunciados en cada una de ellas, "cercanía" y "lejanía" en una idéntica sonoridad. La siguiente sección (13) -“Constelación de las estrellas del amor [...]" (cc. 265-290)- comienza con una presentación instrumental que remite al inicio de la cantata, con un mayor cromatismo que desdibuja la armonía y en la que se contrapone la progresión ascendente de la cuerda (cc. 265-272) a la progresión descendente del quinteto de cuerdas a solo (cc. 273-276). Los versos "Constelación de las estrellas del amor. / Constelación de las estrellas de la paz" serán cantados a capella con un ágil comentario de la cuerda en seisillos, y preparan el último verso de la composición "Constelación de las estrellas de la unión entre los pueblos que proclaman la vida" (cc. 282-290), donde se alargan los valores. En este punto la homofonía entre sopranos, altos y bajos subraya "la unión entre los pueblos" -proclamada a solo por los tenores (cc. 287-288)-, y se alcanza el máximo melódico a capella en "que proclaman la vida" (c. 290) sobre esa concatenación armónica de intervalo de tercera -casi temática, FaM / LaM-, que permite cantar en segunda inversión el acorde desnudo de LaM. A partir de este momento, la obra se extingue en una doble coda. La primera de ellas (14, cc. 291-309), marcada por el cambio de tempo (Allegro, $\delta .=152$ ), evocará dos veces la palabra "vida" sobre un pedal de $M i$ en el contexto de $L a M$, conduciendo la música a Re bM. En la segunda (15, cc. $310-319)$, se repite cinco veces la palabra "vida" sobre las figuraciones ambiguas mayor/menor de vibráfonos y marimbas en las que triunfa finalmente la tonalidad de $M i b M$. En total, y tras la enunciación completa del último verso, se suceden siete ecos de la palabra "vida", como destellos de las estrellas invocadas, en una obra, como dijimos, dividida en dos grandes partes con siete subsecciones cada una de ellas y articuladas por un eje central que anticipa en la sección áurea de la composición el máximo melódico sobre la palabra "vivificadora", anticipación del máximo conclusivo "vida” (c. 290). Una estructura que la naturaleza de los acontecimientos revelaría, sin duda, en su verdadera dimensión social y colectiva.$$
\text { 1. Introducción instrumental. cc.1-30 }
$$

2. Siete estrellas $[\ldots]$ cc. $3-68$

3. Constelación inspiradora y cercana [...] cc. 68-106 4. Luz inextinguible [...] cc. 107-128

5. Áureos diseños [...] cc. 129-139

6. Interludio instrumental cc. $140-160$

7. Estrella de las blancas cumbres [...] cc. 161-169

* Estrella del pensamiento universal cc. 170-201

9. Estrella que proclama el amor cc. 202-220

10. Estrella que ilumina el pensamiento [...] cc. 220-232

11. Estrella que eleva en incesante vuelo [...] cc. 232-253 12. Siete estrellas [...] cc. 253-264

13. Constelación de las estrellas del amor [...] cc. 265-290

14. Coda 1. Vida, vida cc. 291-309

15. Coda 2. Que proclaman la vida, la vida, la vida, la vida, la vida cc. 310-319. 


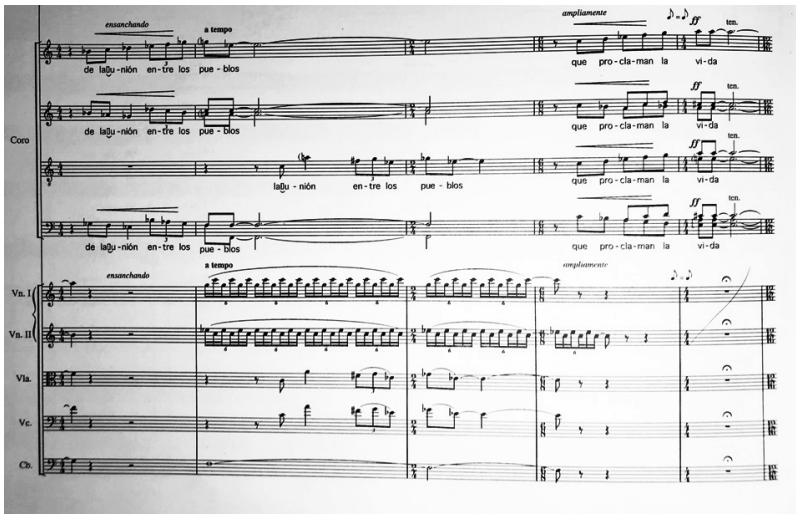

Fig. 2. Cántico de las siete estrellas, cc. 286-290, Madrid, Bolamar, 2006, 50.

\section{CONCLUSIONES}

Cántico de las siete estrellas constituye, en consecuencia, una composición comisionada y creada para celebrar "la unión de los pueblos que proclaman la vida", construida no solo sobre los vestigios emblemáticos -depositarios de una historia plural forjada por los distintos pueblos que habitaron Madrid, así como por la convivencia de sus distintos saberes y escuelas-, sino también sobre una reinterpretación de la literatura humanística que presidió el primer paso de su historia como transformación en Corte del Estado en 1561. Esta escritura celebrativa, sin embargo, se vio transida en sus momentos finales por el atentado terrorista del 11.03.2004, a cuyas víctimas es finalmente dedicada esta obra. El golpe de la realidad transforma las coordenadas de sentido y reescribe nuevos valores tanto sobre la filiación textual del patrimonio literario humanístico al que se dirige Antón García Abril, como sobre los recursos compositivos que dispone en la obra no solo en su dimensión estructural, sino también los empleados al servicio de la palabra como instrumentos iluminadores del discurso. Un ejemplo, en definitiva, de que el sentido último de cualquier obra musical deviene como construcción social que reubica y condiciona las estructuras portadoras de significado en la dimensión pragmática de ese mínimo observador insignificante en el cosmos que durante su breve existencia como especie no se cansa de perder su mirada en la infinitud inquisidora de la bóveda celeste.

\section{BIBLIOGRAFÍA}

AA.VV., Once voces contra la barbarie del 11-M. Madrid, SGAE, 2006.

Alfonso X el Sabio, Setenario. Vanderford, Kenneth H. (ed. e intr.) y Lapesa, Rafael (estudio). Barcelona, Crítica, 1984.

Alonso, Gonzalo, "Entre Antones", Beckmesser, Crítica. 29.11.2009. Acceso: 3 de noviembre de 2017 https:// www.beckmesser.com/entre-antones/

Álvarez y Baena, Josef Antonio, Compendio Histórico de las grandezas de la coronada Villa de Madrid. Madrid, Antonio Sancha, 1786.

Arellano, Ignacio, "Un pasaje oscuro de Góngora aclarado: el animal tenebroso de la Soledad primera (vv. 64-83)", Criticón, CXX-CXXI (Pamplona, 2014), 201-233.

Ávila, María Luisa, "Personajes del Madrid islámico", Gil Flores, Daniel (ed.), De Maŷrit a Madrid. Madrid y los árabes, del siglo IX al siglo XXI. Madrid / Barcelona, Casa Árabe / Lunwerg, 2011, 54-65.

Baztán Vergara, Francisco, Manual informativo de la villa de Madrid. Madrid, Ayuntamiento de Madrid, 1967.

Bribitzer-Stull, Matthew, "The A-flat-C-E complex: the origin and function of chromatic major third collections in nineteenth-century music", Music Theory Spectrum, XXVIII/2 (Oxford, 2006), 167-190.

Cabañas Alamán, Fernando, Antón García Abril: sonidos en libertad. Madrid, Instituto Complutense de Ciencias Musicales, 1993.

Carbó Montaner, Claudio, El piano de Antón García Abril: cénit de inspiración compositiva en su madurez creativa. Tesis doctoral, Zaragoza, Universidad de Zaragoza, 2016.

Castro Pérez de Castro, Emilio, "Sobre el emblema y el escudo de Madrid”, Madrid histórico, X (Madrid: 2007), 70-73.

Coomaraswamy, Ananda. K. Selected Papers. Metaphysics. Princeton, Princeton University Press, 1977.

Coronas Valle, Paula, La obra pianística de Antón García Abril: un paradigma de comunicación musical. Tesis doctoral, Málaga, Universidad de Málaga, 2008.

Coronas Valle, Paula, La obra pianística de Antón García Abril: enfoque estético y comunicativo de su mensaje. Málaga, Universidad de Málaga, 2010.

Coulter-Smith, Graham, Visualizando lo indecible: reflexiones sobre el arte en la era del terrorismo. Imaging the Unspeakable: Reflections on Art in the Age of Terrorism. Madrid, Brumaria, 2009.

Domínguez Rodríguez, Ana, “Astrología y mitología en los manuscritos ilustrados de Alfonso X El Sabio", En la España Medieval, XXX (Madrid: 2007), 27-64.

Fernández de la Cuesta, Ismael, “Antón García Abril, defensor de la melodía”, Nassarre, XIX/1 (Zaragoza, 2003), 195204.

Fray Luis de León, Obras completas castellanas. Madrid, Biblioteca de Autores Cristianos, 1944.

Fray Luis de León, Poesía completa. Blecua, José Manuel (ed.). Madrid, Gredos, 1990.

Gangi, Jane M. y Barwosky Ellis, "Listening to Children's Voices. Literature and the Arts as Means of Responding to the Effects of War, Terrorism, and Disaster", Chidlhood Education, LXXXV/6 (Londres, 2009), 357-363.

García Abril, Antón, "Notas al programa: Auditorio Nacional. Ciclos Musicales de la Comunidad de Madrid", Madrid, Consejería de Cultura y Deportes, 27.04.2004.

García Abril, Antón, Cántico de las siete estrellas (para coro y Orquesta). Madrid, Bolamar, 2006.

García Laborda, José María, "San Francisco de Asís y el Can- 
tico delle Creature en la música de Antón García Abril y de otros compositores del siglo XX", Nassarre, XIX/1 (Zaragoza, 2003), 205-255.

Gaviña, Susana, "Música para las Madres dolorosas", $A B C$ (Madrid, 06.03.2005): 81.

Guerra Chavarino, Emilio, "Los escudos de Madrid a lo largo de su historia", Anales del Instituto de Estudios Madrileños, L (Madrid, 2010), 245-276.

Huidobro Moya, José Manuel, "Evolución del escudo de Madrid", Hidalgos: la revista de la Real Asociación de Hidalgos de España, DXLVII (Madrid: 2016), 32-36.

Iglesias, Antonio, "Cántico a la paz y a los pueblos", $A B C$, martes, 04.05.2004, 60.

Jou i Mirabent, David, “Astronomia i poesía", Mètode: Revista de difusió de la investigació de la Universitat de Valencia, XXXVII (Valencia, 2003), 33-40.

Kohl, Jerome, "Harmonies and the Path from Beauty to Awakening: Hours 5 to 12 of Stockhausen's Klang", Perspectives of New Music, L/1-2, (Seatlle, 2012), 476-523.

López de Hoyos, Juan, Historia y relación verdadera de la enfermedad, felicísimo tránsito y sumtuosas exequias fúnebres de la serenísima reyna de España Doña Isabel de Valois, nuestra señora. Madrid, Pierres Cosín, 1569. Edición facsimilar en Madrid, Ábaco ediciones, 1976.

López Sánchez, Laura, "La barbarie del 11-M en el teatro español”, Signa, XX (Madrid, 2011), 101-118.

Marazuela, Anna, "Art and Terrorism Symposium Review", Journal of Art Crime, XV (2016), 107-110.

Mateo del Peral, L. Regino, "El oso u osa en el escudo de la villa”, Madrid histórico, XXXIV (Madrid, 2011), 24-31.

Palacios Sanz, José Ignacio. "Antón García Abril y la Universidad”, Nassarre, XIX/1 (Zaragoza, 2003), 453-468.

Pärt, Arvo, Da pacem Domine. Viena, Universal Edition, 2006.

Pastor Comín, Juan José, "Sobre el romancero musical de Lope de Vega", Anuario Lope de Vega, IV (Barcelona, 1998), 297-310.

Pérez de Arteaga, José Luis, “Canciones por la paz. Notas al programa". Madrid, Centro Superior de Investigación y Promoción de la Música, 2015.

Phelan, Helen, "Hortus Deliciarum / Garden of Delights: A Somatic Interpretation", Nature, Culture \& Literature, XIII (Boston, 2017), 60-75.

Putnam, Michale T., "Music as a Weapon Reactions and Responses to RAF Terrorism in the Music of Ton Steine
Scherben and their Successors in Post-9/11 Music", Popular Music and Society, XXXII/5 (Ohio, 2009), 595606.

Ritter, Jonathan y Daughtry, J. Martin (eds.), Music in the Post9/11 World. Nueva York/Londres, Routledge, 2012.

Robledo Estaire, Luis, "La música, intermediaria entre el saber humano y la piedad: la Alegoría de las artes liberales de Miguel March (ca. 1633-1670)", Revista catalana de musicología, V (Barcelona: 2012), 31-51.

Ruiz Tarazona, Andrés, Antón García Abril, un inconformista. El compositor, visto y sentido por sus intérpretes. Madrid, Fundación Autor, 2005.

Russomano, Stefano, "Notas al programa: Concierto 7, Ciclo I. 27,28 y 29 de noviembre de 2009". Madrid, Orquesta y Coro Nacionales de España, 2009, 5-11.

Sánchez Alonso, Cristina, Impresos de los siglos XVI y XVII de temática madrileña. Madrid, CSIC, 1981.

San Llorente Pardo, Inés, Música y policía en la España del desarrollismo (1962-1970). Tesis doctoral, Albacete, Universidad de Castilla-La Mancha, 2018.

Sestelo Longueira, Esther, Antón García Abril: el camino singular de un humanista en la vanguardia, continuador de la cultura española de su tiempo. Tesis doctoral, Universidad Complutense de Madrid, 2006.

Soria, Yanira, Antón García Abril: "Alba de los caminos" and the Concept of Polimelodiosidad. Tesis doctoral, Houston (Texas), University of Houston, 2016.

Suñén, Luis, "Temporadas Temáticas", Pons, Josep (ed.), Memoria OCNE. Madrid, Orquesta y Coro Nacional de España, 2013, 30-53.

Torres, Rosana, “Once voces en la escena”, Diario El País (Madrid, 10.03.2005).

Vega, Lope de, Los locos de Valencia. Tropé, Hélène (ed.). Madrid, Castalia, 2003.

Velescu, O. "George Crumb and the Music of Stars: Makrokosmos", $2^{\text {nd }}$ International Multidisciplinary Scientific Conference on Social Sciences and Arts. Sofia, SGEM2015, IV/1 (2015), 93-98.

Zaldívar Gracia, Álvaro, "In honorem Antón García Abril (Teruel, 1933)”, Nassarre, XIX/1 (Zaragoza, 2003), 7-85.

Zydorowicz, Jacek, "Art and Terrorism as Catalysts of Social Tensions”, Art Inquiry, XII (Varsovia, 2010), 201-217.

Recibido: 09.04.2018

Aceptado: 16.04.2018 